\title{
AC 2007-40: HISTORY AND TRIVIA TO ENLIVEN DYNAMICS
}

\section{Phillip Cornwell, Rose-Hulman Institute of Technology}

Phillip Cornwell is a Professor of Mechanical Engineering at Rose-Hulman Institute of Technology. He received his Ph.D. from Princeton University in 1989 and his present interests include structural dynamics, structural health monitoring, and undergraduate engineering education. Dr. Cornwell has received an SAE Ralph R. Teetor Educational Award in 1992 and at Rose-Hulman he has received the Dean's Outstanding Teacher award in 2000 and the Board of Trustees Outstanding Scholar Award in 2001. 


\section{History and Trivia to Enliven Dynamics}

Galileo was an excellent lute player. A quote about Gottfried Leibniz is: "It is rare to find learned men who are clean, do not stink and have a sense of humor." Sir Isaac Newton was under 25 years old when he began making revolutionary advances in mathematics, optics, physics, and astronomy. Leonard Euler had 13 children and was blind the last 17 years of his life. Blindness did not seem to hinder him in any way, however, since he produced almost half of his total works while he was completely blind. Students of dynamics will typically be familiar with the names of many of the historical figures critical to the development of dynamics, but be completely unaware of when they lived or what they actually contributed. This information, plus additional trivia, can be used to enliven dynamics and to keep students' interest. The primary purpose of this paper is to provide short biographies of the major historical figures in the history of dynamics as a resource for mechanics educators. These short biographies contain not only information about when they lived and their contributions to dynamics, but also pieces of trivia, quotes about them or by them, and other interesting facts. Suggestions will be made as to how this material can be used in class, and survey results will be presented on how students felt about this material.

\section{Introduction}

In many disciplines, architecture for example, students are typically taught about the history of their discipline. Engineers, however, are usually woefully uneducated about the history of their discipline. History, however, can be used to help students put faces to the names they hear when they study dynamics and can be useful in engaging their interest and enlivening the subject. This is true of engineering design as well as engineering science. In this paper, a brief history of dynamics from Newton to Hamilton will be presented. This material can be used at the beginning of a lecture or sprinkled throughout to add some color to a lecture. The reference used for much of this historical information is the wonderful first chapter of Fundamentals of Applied Dynamics by James Williams. ${ }^{1}$ The biographical information came primarily from a couple of great websites, The MacTutor History of Mathematics Archive ${ }^{2}$ and Eric Weissteins' World of Scientific Biography, ${ }^{3}$ both of which have huge collections of short biographies.

Dynamics has evolved along two primary lines of thought, the direct approach and the indirect approach. Some of the main contributors to each approach are shown in Figure 1.

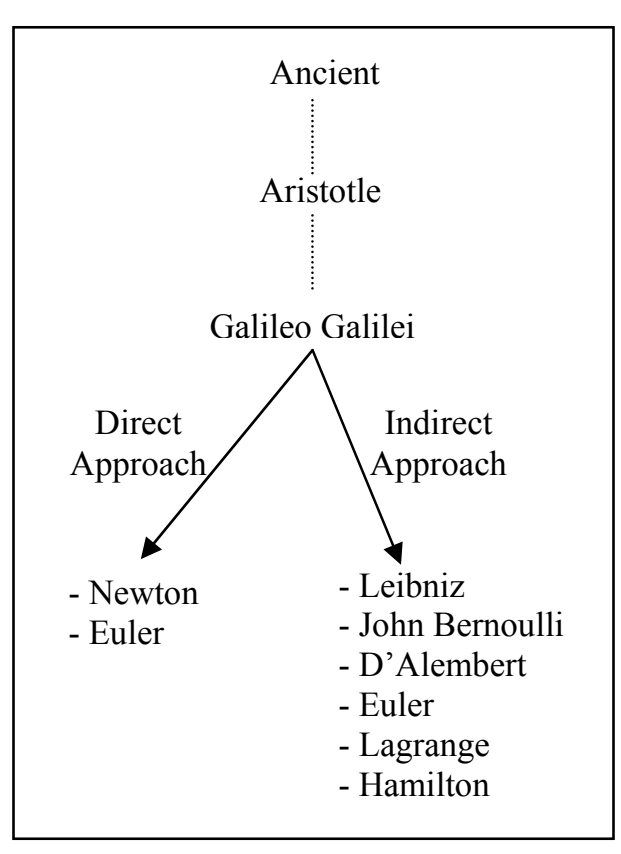

Figure 1 Two lines of thought when solving dynamics problems

The direct approach, also called vectorial dynamics, has the following characteristics:

- Force and momentum are the primary parameters.

- Newton's laws are considered directly, so we get vector equations. 
The indirect approach, or variational dynamics (also called analytical dynamics), is an alternative method of obtaining governing differential equations and is characterized by the following:

- Forces that do no work do not need to be considered.

- Accelerations do not have to be computed, only velocities.

- In general, operations are on scalars not vectors.

A timeline showing when some of the primary contributors to dynamics lived is shown in Figure 2. The number in the bar is how old he was when he died, and the number on the left is the year of his birth. The purpose of this figure is to give you a sense of when they lived relative to each other and how most of the material covered in a typical sophomore level dynamics course is really quite old.

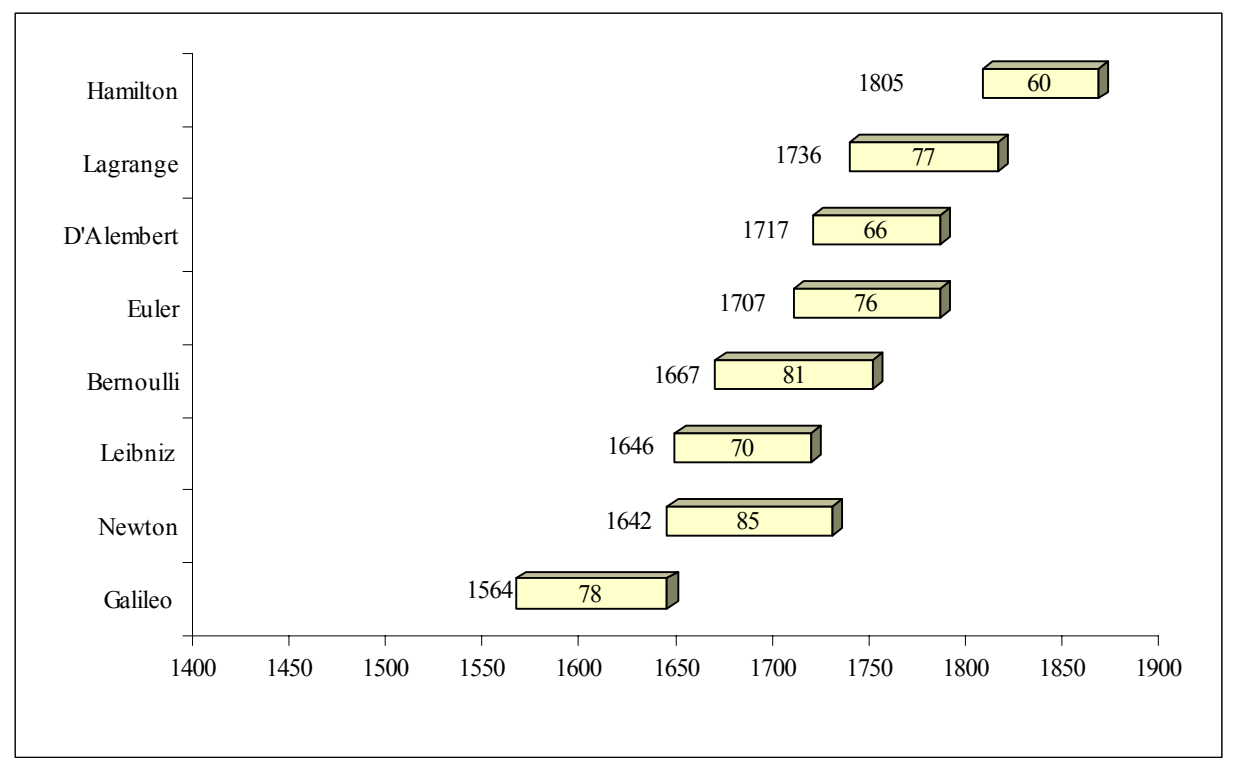

Figure 2 Some of the primary contributors to dynamics and when they lived.

It is important to recognize that there are additional individuals who were clearly important to the development of dynamics, but in this paper the focus will be on those who were, in the author's opinion, the major contributors. Brief summaries of the lives of these men, and a few earlier ones, and some of their contributions to the field of dynamics are discussed below.

\section{Historical Profiles}

Aristotle (384-322 B.C.)

Aristotle is generally classified as one of the greatest philosophers of all time. The main reason for briefly mentioning him in this short discussion of the history of dynamics is that his works were accepted as fact for a very long time. Quoting D. J. Allan from The Philosophy of Aristotle: ${ }^{4}$

"Aristotle, more than any other thinker, determined the orientation and the content of Western intellectual history. He was the author of a

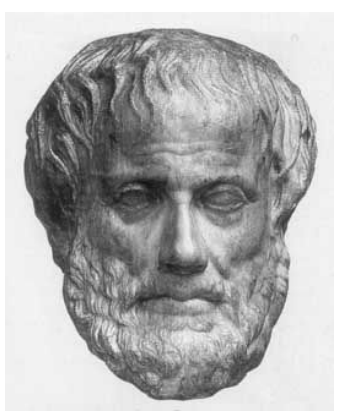

Aristotle $^{2}$ 
philosophical and scientific system that through the centuries became the support and vehicle for both medieval Christian and Islamic scholastic thought: until the end of the 17th century, Western culture was Aristotelian. And, even after the intellectual revolutions of centuries to follow, Aristotelian concepts and ideas remained embedded in Western thinking."

He did work in fields that we now classify as biology, astronomy, physics, chemistry, logic, metaphysics, theology, psychology, politics, economics, and others. Aristotle was the first to conceive of and establish many of these fields of study as systematic disciplines. From Treatise on the Heavens and Physics, his views regarding terrestrial motion can be summarized as follows:

- The natural state of all earth bound bodies is rest (zero velocity).

- Objects fall in a straight line.

- Heavy objects fall faster than light objects.

- If a given object falls from a certain height in a particular time interval, an object that is twice as heavy will fall from the same height in half the time interval.

Based simply on observation, all of these propositions sound perfectly reasonable and are consistent with everyday experience, however, they are wrong. This was basically the state of understanding for approximately 2000 years.

Some trivia about and quotations made by Aristotle:

- The often quoted story that he became tutor to the young Alexander the Great, the son of Philip, is almost certainly a later invention. ${ }^{5}$

- Aristotle was the one who said "The whole is more than the sum of its parts.",

- Aristotle also stated "That which we must learn to do, we learn by doing,", which can be used to encourage students to do homework.

Galileo Galilei (1564-1642)

Galileo was a true Renaissance man. Not only was he a philosopher and scientist, but also an excellent lute player (his father was a professional musician) and painter. He attended medical school in Padua, and in 1592 he was appointed professor of mathematics at the university there. He primarily taught geometry and standard (geocentric) astronomy to medical students. You must remember that times were quite different then and so was the medical profession. His students were required to know some astronomy in order to make use of astrology in their medical practice.

Galileo built his own telescope in 1609, and he discovered craters and mountains on the moon, sun spots, the four largest moons of

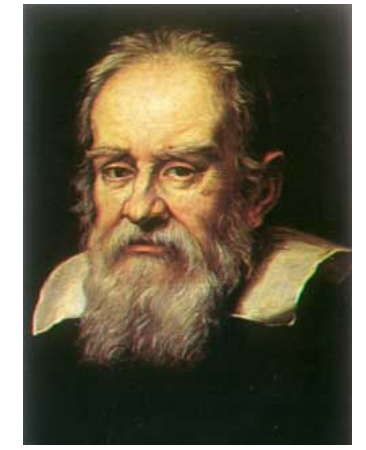

Portrait of Galileo by Justus Sustermans painted in $1636^{2}$ Jupiter, and that the planet Venus showed phases like those of the moon, indicating that it must orbit the sun rather than the Earth.

In this paper only a few of his ideas which strongly influenced dynamics will be mentioned. By 1604 he had determined the correct relationship for falling bodies $\left(\mathrm{d} \propto \mathrm{t}^{2}\right)$ and had stated that bodies of different weights should fall at the same speed (the difference being because of air 
resistance). In Dialogue Concerning the Two Chief World Systems (1632), he conducted a thought experiment in which he concluded that the natural state of motion for a body is constant velocity. This was a key to the concept of inertia and to the development of dynamics.

Dialogue Concerning the Two Chief World Systems was supposed to be an objective debate between the Copernican and Ptolemaic systems. Unfortunately, Galileo put the Pope's favorite argument in the mouth of one of the characters, then proceeded to ridicule it (which, by the way, is not a good idea unless you happen to be a good friend of the Pope, and you know he has a good sense of humor, which Galileo was not, and the Pope did not). Galileo suddenly lost favor with the church, was forced to recant his Copernican views, and was condemned to house arrest, for life, at his villa at Arcetri (above Florence). He was also forbidden to publish.

Some of Galileo's quotations ${ }^{2}$ :

- "I have never met a man so ignorant that I couldn't learn something from him."

- "All truths are easy to understand once they are discovered; the point is to discover them."

Isaac Newton (1642-1727)

The most famous person associated with the study of dynamics is obviously Sir Isaac Newton, affectionately called "needle nose Newton" by his closest friends. That last part is not true, so please do not quote me. Newton made truly amazing contributions to science and mathematics. As famous poet Alexander Pope wrote:

"Nature and Nature's laws lay hid in night; God said, Let Newton be! and all was light."

Newton was still under 25 years old when he began making revolutionary advances in mathematics, optics, physics, and astronomy. Newton invented calculus, the 'method of fluxions', as he termed it, years before Leibniz, although he did not publish his work. This led to a significant conflict between those supporting Newton and those supporting Leibniz, basically, English and continental

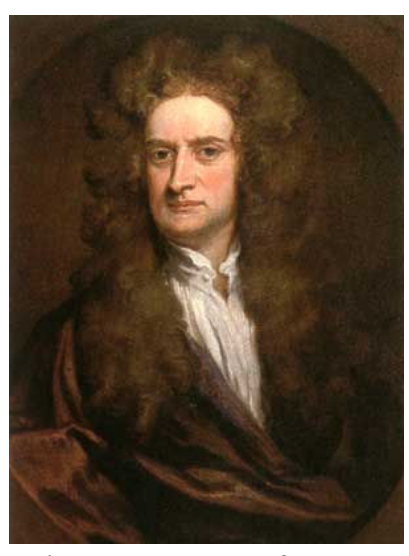

Sir Isaac Newton from a portrait by Kneller in $1702^{2}$. This is in the National Portrait Gallery in London. mathematicians, respectively. Although Newton is now generally acknowledged as having done the work earlier than Leibniz, Leibniz had a superior notation, a notation that is still used today. Newton was responsible for the $\dot{f}(x)$ and $f^{\prime}(x)$ notations, and Leibniz was responsible for the $\frac{d}{d x}$ notation. In his Quadratura curvarum of 1704 , Newton indicated the integral of $\mathrm{x}$ using a small vertical bar above $\mathrm{x}$ such as $\mathrm{x}$. He wrote two side-byside vertical bars over $\mathrm{x}$ to indicate the integral of $\mathrm{x}$ with a single bar over it. Alternatively, Newton would place the variable inside a box to indicate it was an integral. Neither one of these notations were widely adopted because the bars could easily be confused with the prime he used for differentiation and the box notation was difficult for printers to reproduce. The modern notation for the indefinite integral was introduced by Gottfried Leibniz in 1675. The integral symbol he used, "I", was derived from an elongated letter S, standing for summa (Latin for "sum" 
or "total"). Newton was at times a very nasty man. Following the death of Leibniz, Newton is reported to have declared that he had taken great satisfaction in "breaking Leibniz's heart."

Newton seemed to be characterized by a lack of publishing for much of his life. This may have been due to the fact that he was very sensitive to criticism. For example, the conflict he had with Robert Hooke over optics resulted in his ceasing all publications until after the death of Hooke in 1703.

Newton's most significant work on physics, generally acknowledged as one of the most important and influential works in science of all time, was called Philosophiae Naturalis Principia Mathematica (Mathematical Principles of Natural Philosophy) (1687), or more commonly referred to as The Principia (1687). This work contains three books. In Book I he states the three laws that he presumes governs the motion of all objects (see Table 1) as well as the law of universal gravitation.

\begin{tabular}{|l|l|l|}
\hline \multicolumn{2}{|c|}{ Table 1 - Newton's Three Laws } \\
\hline Law & $\begin{array}{l}\text { Original statement } \\
\text { Every body continues in its state of } \\
\text { rest or of uniform motion in a right } \\
\text { line, unless it be compelled to change } \\
\text { that state by forces impressed upon it. }\end{array}$ & $\begin{array}{l}\text { A particle remains at rest or continues to } \\
\text { move in a straight line with constant } \\
\text { velocity if there is no resultant force } \\
\text { acting on it. }\end{array}$ \\
\hline 2 & $\begin{array}{l}\text { The change of motion is proportional } \\
\text { to the motive force impressed; and is } \\
\text { made in the direction of the right line } \\
\text { in which that force is impressed. }\end{array}$ & $\begin{array}{l}\text { A particle acted on by a resultant force } \\
\text { moves in such a manner that the time rate } \\
\text { of change of its linear momentum is equal } \\
\text { to the force. }\end{array}$ \\
\hline 3 & $\begin{array}{l}\text { To every action there is always } \\
\text { opposed an equal reaction; or, the } \\
\text { mutual actions of two bodies upon } \\
\text { each other are always equal, and } \\
\text { directed to contrary parts. }\end{array}$ & $\begin{array}{l}\text { Forces result from the interaction of } \\
\text { particles and such forces between two } \\
\text { particles are equal in magnitude, opposite } \\
\text { in direction, and collinear. }\end{array}$ \\
\hline
\end{tabular}

Later in life, Newton worked as a highly paid government official in London (he was Warden of the Royal Mint) with little further interest in mathematical research. Newton believed deeply in the necessity of a God. His theological views, as articulated in The Principia, were characterized by his belief that the beauty and regularity of the natural world could only "proceed from the counsel and dominion of an intelligent and powerful Being." He felt that "the Supreme God exists necessarily, and by the same necessity he exists always and everywhere." Newton devoted a majority of his free time later in life (after 1678) to fruitless alchemical experiments, which likely explains the large amount of mercury that was found in his body following his death. 
Finally, a few quotes attributed to him:

"I know not what I appear to the world, but to myself I seem to have been only like a boy playing on the sea-shore, and diverting myself in now and then finding a smoother pebble or a prettier shell, whilst the great ocean of truth lay all undiscovered before me." Quoted in Memoirs of Newton by D. Brewster. ${ }^{8}$

"If I have been able to see further, it was only because I stood on the shoulders of giants," from a letter to Robert Hooke in 1676. Although this statement is usually used as an example of Newton's humility, it is interpreted by some people to be an insult to Hooke. Hooke was described by his contemporaries as short and with a twisted spine. Newton's reference to 'giants' alludes, perhaps, to Hooke's lack of physical stature. In fact, Newton was not even the first to use the line. Some scholars attribute the original to Bernard of Chartres in 1130 who stated:

"We are like dwarfs standing [or sitting] upon the shoulders of giants, and so able to see more and see farther than the ancients" - Bernard of Chartres, circa 1130

Gottfried Leibniz (1646-1716)

Leibniz was a German philosopher, mathematician and physicist (you will note that at this time there was not much of a distinction between these fields). Leibniz made major contributions to the field of mathematics and is credited with developing calculus independent of Newton (and with much superior notation that is still in use today as discussed earlier). He did work in the area of differential equations, as well as many other areas, but let's talk about his more interesting work in the area of dynamics.

Leibniz was a strong believer in what he called vis visa, the living force, which was equal to $\mathrm{mv}^{2}$. He believed his vis visa to be the most fundamental quantity (in contrast to Descartes' momentum, mv) for describing motion. He believed the amount of vis visa did

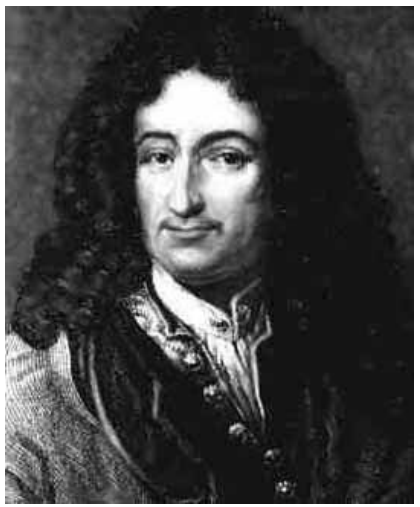

Portrait of Gottfried Leibniz $^{2}$ not change, and his statements come very close to an early statement of conservation of energy. This was the beginning of what we now call "energy methods" in dynamics. He argued for this conserved quantity, not so much on the basis of experimentation, since inelastic collisions seem to contradict his assertion that this quantity did not change, but more from a belief in the order and continuity of the world. He believed the world had order because it had been created by God.

Finally, I want to share how some others have described him. In the biography of Leibniz in Encyclopaedia Britannica, ${ }^{9}$ he is described as follows:

"Leibniz was a man of medium height with a stoop, broad-shouldered but bandy-legged, as capable of thinking for several days sitting in the same chair as of traveling the roads of Europe summer and winter. He was an indefatigable worker, a universal letter writer 
(he had more than 600 correspondents), a patriot and cosmopolitan, a great scientist, and one of the most powerful spirits of Western civilization."

Another quote about him attributed variously to Charles Louis de Secondat Montesquieu and to the Duchess of Orléans:

"It is rare to find learned men who are clean, do not stink and have a sense of humor."

Finally, one last piece of trivia about Leibnitz is that he was the person who introduced the dot as a symbol for multiplication. On July 29, 1698, he wrote in a letter to Johann Bernoulli: "I do not like $\mathrm{X}$ as a symbol for multiplication, as it is easily confounded with $x$..." Quoted in F Cajori, A History of Mathematical Notations (1928). ${ }^{10}$

In addition to his work in developing calculus, Leibniz was also an engineer and an inventor. He designed wind-driven propellers and water pumps, mining machines, hydraulic presses, lamps, submarines, clocks, etc. Leibniz is also known for constructing a mechanical computing machine, the "Stepped Reckoner". Leibniz' design improved upon one by Pascal and was able to perform four basic arithmetical operations: addition, subtraction, multiplication and division. A picture of Leibniz' Stepped Reckoner is shown in Figure 3.

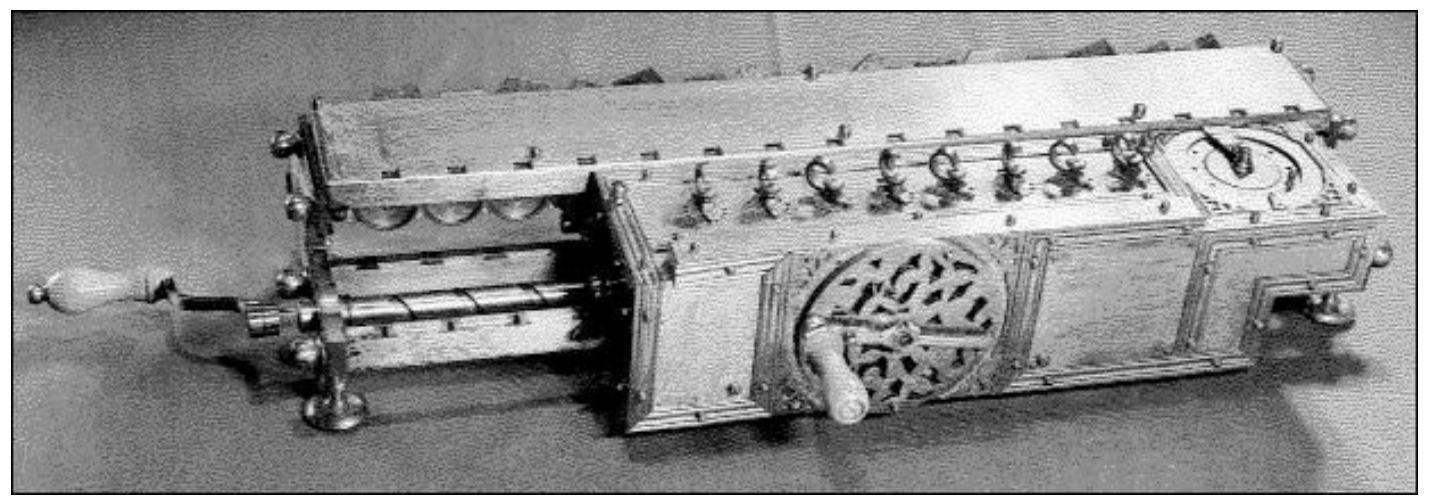

Figure 3 Leibniz' Stepped Reckoner ${ }^{11}$

John Bernoulli (1667-1748)

The Bernoulli family was truly amazing in the number of family members who made significant contributions to mathematics and science. They were also a family beset with jealousy, rivalry and bitterness. In other words, their family reunions were probably not very fun, and not only because they were a bunch of mathematicians (the author feels free to say this because his father was a mathematician). There are quite a number of things that have been named "Bernoulli's_ such as "Bernoulli's Equation," "Bernoulli Numbers," "Bernoulli's Principle" and so on. Unfortunately, they usually do not refer to the same Bernoulli. A Bernoulli family tree is shown in Figure 4 (only the family members who were well known mathematicians are shown.) Although this

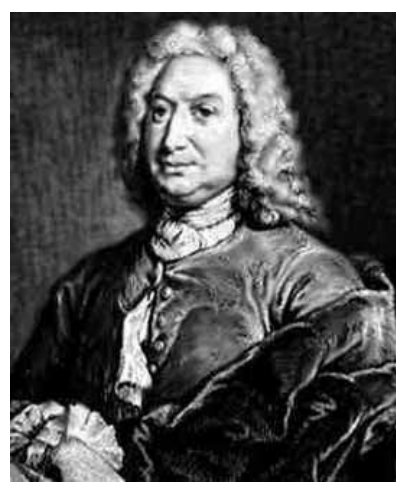

Portrait of John Bernoulli ${ }^{2}$ paper will talk about Johann (John) Bernoulli the most, it is 


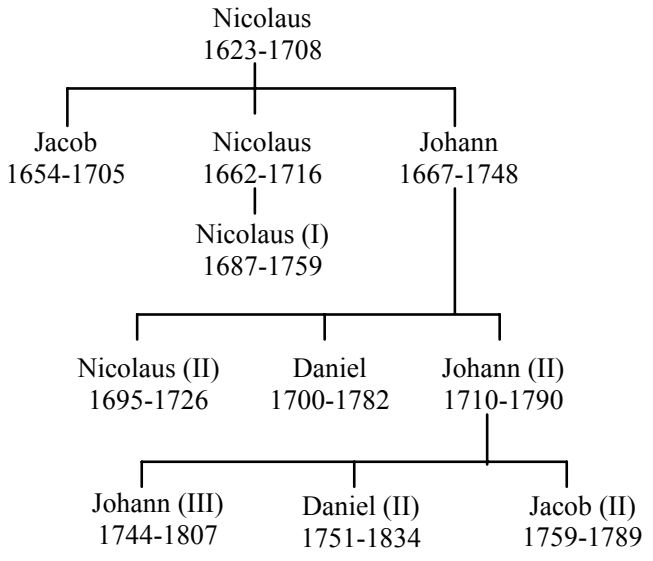

Figure 4 - Members of the Bernoulli family who were excellent mathematicians and/or physicists. insightful to learn something of the others and some of the things named after them.

In mathematics, Bernoulli's equation $y^{\prime}=p(x) y+q(x) y^{n}$ is named after Jacob Bernoulli, as are the Bernoulli numbers. Daniel Bernoulli showed that as the velocity of a fluid increases, the pressure decreases, a statement known as the Bernoulli Principle, and the equation describing the flow of an incompressible, inviscid, steady fluid is called Bernoulli's equation. He also won the annual prize of the French Academy ten times for work on vibrating strings, ocean tides, and the kinetic theory of gases. Only Leonhard Euler won this prize more times.

In the field of mechanics John (Johann) Bernoulli made significant contributions. In a letter in 1717 he precisely formulated the "Principle of Virtual Work" (for all admissible variations, the sum of all the work done by the forces must vanish if the forces are in equilibrium) which is a crucial concept in variational dynamics. Now some trivia: All engineers are familiar with l'Hospital's rule. It turns out that Johann instructed l'Hospital in calculus. L'Hospital later wrote a textbook based on Bernoulli's instruction to him, and in this book he included what is now known as l'Hospital's rule. This rule had actually been developed by Bernoulli. It is probably better that it was not proved to be John's result before 1922, because there would have been something else named after a Bernoulli, Bernoulli's rule. John Bernoulli's most famous student was Leonhard Euler.

\section{Leonhard Euler (1707-1783)}

All of the men discussed in this paper were extremely brilliant and hardworking, but Euler stands out as particularly amazing. It is reported that he once did a calculation in his head to settle an argument between two of his students whose computations differed in the fiftieth decimal place. He also appears to have had a photographic memory. It is said that early in his life he memorized the entire Aeneid by Virgil, and at age 70 he could not only recite the entire work, but could also state the first and last sentence on each page of the book he had memorized it from. His memory and his ability to do calculations and analysis in his head served him well considering the fact that he was totally blind the last 17 years of

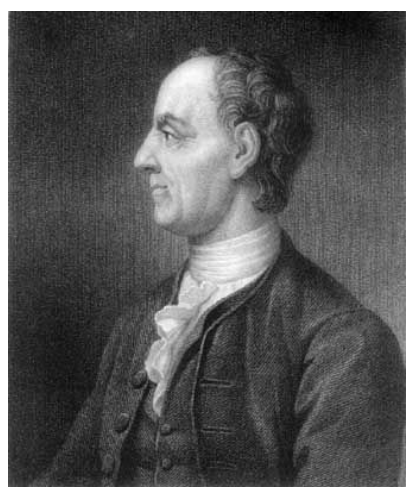

Portrait of Leonhard Euler ${ }^{2}$ his life. Blindness did not seem to hinder him in any way since he produced almost half of his total works while he was completely blind. Euler was the most prolific writer of mathematics of all time, averaging 800 printed pages/year throughout his life. When asked for an explanation why his memoirs flowed so easily in such huge quantities, Euler is reported to have replied that "his pencil seemed to surpass him in intelligence." His choice of Leibniz's differential notation led the way towards our modern notation and techniques in mechanics. He made major contributions in dynamics, solid mechanics, fluid mechanics, optics, electricity, magnetism, and mathematics to name a few fields. Over 30 quantities (equations, 
numbers, theorems, etc) are named after him. For example: Euler's formula $\left(\mathrm{e}^{\mathrm{i} \theta}=\cos \theta+\mathrm{i} \sin \theta\right)$, Euler's Equation (in the calculus of variations), Euler's Equation (in differential equations), Euler's Equation (for the motion of an ideal fluid), and Euler's Equations (for the rotation of a rigid body) just to name a few. In other words, just saying "Euler's Equation" doesn't give nearly enough information because there are too many equations named after him.

Euler made major contributions in the area of mechanics. Euler was the person to extend Newton's concepts to rigid bodies (Newton was basically concerned with particles), so if a student does not like rigid body dynamics (which is hard to imagine since it is much more interesting and fun than particle dynamics), they have Euler to blame and not Newton. Euler had several major works in mechanics including Mechanica (1736), which provided a major advance in mechanics primarily due to the systematic and successful way he presented Newtonian dynamics in the form of mathematical analysis for the first time. In 1765 he published Theoria motus corporum solidorum (Theory of the Motions of Rigid Bodies) in which he decomposed the motion of a solid into a rectilinear motion and a rotational motion and laid the foundation of analytical mechanics. Euler's work provided the key to solving such problems as the movement of gyroscopes, spinning tops, the nutation of the earth, and a host of related problems. A major step toward the solution of such problems was the definition of concepts such as the "center of inertia" and the "moment of inertia," which Euler first calculated for various homogenous bodies.

Finally, here are a few quotes and a final comment on this amazing man. In a testament to Euler's proficiency in all branches of mathematics, the great French mathematician Laplace (known for the Laplace transform) told his students, "Liesez Euler, Liesez Euler, c'est notre maître à tous" ("Read Euler, read Euler, he is our master in everything." ${ }^{12}$ Euler also had 13 children (although only five of them lived to adulthood) and he claimed that some of his greatest discoveries were made while holding a baby in his arms with his other children playing around his feet. Based on everything the author read in studying Euler, in addition to being brilliant and extremely hard working, Euler was a gracious and unselfish person, a loving father, a teacher, and a man of deep faith and conviction.

Jean Le Rond d'Alembert (1717-1783)

D'Alembert was a French mathematician. With Diderot he worked on the 28 volume encyclopedia Dictionaire raisonné des sciences, des arts et des métiers (the first volume appeared in 1751). D'Alembert wrote most of the mathematical and scientific articles and the work was widely acclaimed. His main contribution to dynamics was in Traité de Dynamique (1743), where he presents what is now known as d'Alembert's principle, which reduces problems of dynamics to statics by adding a new force called the "inertial force" $(\mathrm{F}-\mathrm{ma}=0)$. Many professors who teach dynamics do not like d'Alembert's principle since mass times acceleration is not really a force, and they hate to see students getting confused. The main reason for including him in this

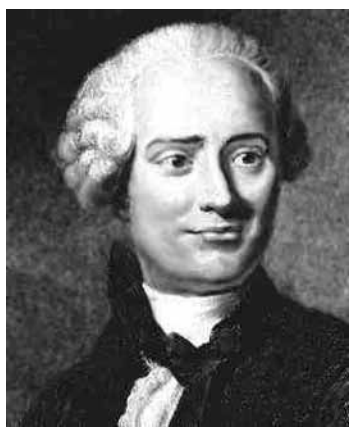

Portrait of Jean Le Rond d-Alembert ${ }^{2}$ brief history is that his work strongly influenced the pursuit and development of the minimum principles by Lagrange and Hamilton. 
One final piece of trivia concerning d'Alembert: As a baby, he was abandoned by his mother on the steps of the church of St. Jean Baptiste de Rond, where he was found and taken to a home for homeless children. He was named after the church.

Joseph-Louis Lagrange (1736-1813)

Lagrange is the first of the men discussed so far who viewed himself almost exclusively as a pure mathematician who sought mathematical elegance. In his most famous work on mechanics, Mechanique Analytique (1788), he states in the preface:

"No diagram will be found in this work. The methods that I explain in it require neither construction nor geometrical or mechanical arguments, but only the algebraic operations inherent to a regular and uniform process. Those who love Analysis will, with joy, see mechanics become a new branch of it and will be grateful to me for thus having extended its field."

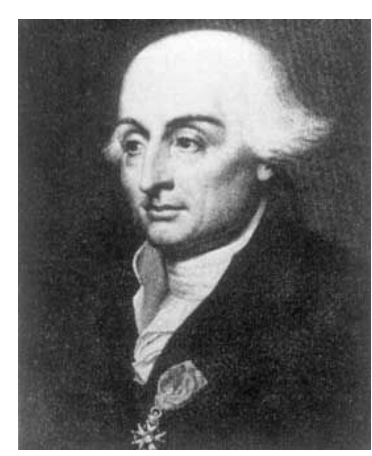

Portrait of Joseph-Louis Lagrange $^{2}$

This view is in complete contrast to what the author emphasizes in his course, but interesting none the less. In Mécanique Analytique, Lagrange summarized all the work done in the field of mechanics since the time of Newton, and it is notable for its use of the theory of differential equations. In this work Lagrange also laid the foundation for variational dynamics, generalized the Principle of Least Action (which states that nature chooses the most economical path for moving bodies and was first formulated by Pierre de Maupertuis), and presented a new and very powerful tool for deriving equations of motion, now called "Lagrange's Equations." Lagrange's Equations are typically not covered in most sophomore level dynamics courses, but if students continue their study of dynamics they will certainly come across them.

\section{Gustave-Gaspard Coriolis (1772-1843)}

Like all of the men discussed in this section, Coriolis was a very bright guy. After all, you do not ask a slacker to succeed Navier (of the famous Navier-Stokes equation in fluids) as the chair of applied mechanics at the École des Ponts et Chaussées and to become a member of the Académie des Sciences as Coriolis was in 1836. To be perfectly honest, however, he usually would not be placed in the same category as those discussed so far. Why then is he included in this section? His name appears when discussing rotating coordinate systems, so it is useful to know something more about him. His primary areas of research were engineering mathematics and mechanics, in particular, friction and machine performance. He introduced the terms "kinetic energy" and "work" with their modern

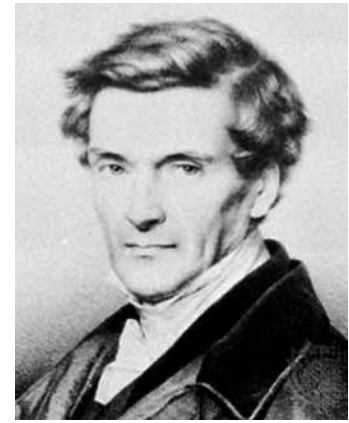

Portrait of GustaveGaspard Coriolis $^{2}$ scientific meanings, but he is best known for the Coriolis acceleration term that appears when using rotating coordinate frames. He first discussed this in the paper Sur les équations $d u$ mouvement relatif des systèmes de corps (1835). Now for some trivia: Coriolis proposed a unit of work, called the 'dynamode' which sounds much cooler than Joule or foot-pound. In 1835 Coriolis wrote on the mathematical theory of billiards in Théorie mathématique des effets du jeu 
de billiard, so students can claim to be examining Coriolis' mathematical theory of billiards while playing pool on a Friday evening.

Sir William Hamilton (1805-1865)

Finally, one other individual will be discussed briefly, William Hamilton. Hamilton extended the formulation of Lagrange by giving the first exact formulation of the Principle of Least Action. This is now called Hamilton's Principle, and similar to Lagrange's Equations, if students continue to study the field of dynamics, they will undoubtedly come across and use Hamilton's Principle at some time. Hamilton also invented quaternions (a non-commutative extension of complex numbers), which are still used in orbital mechanics, mainly for representing rotations and orientations.

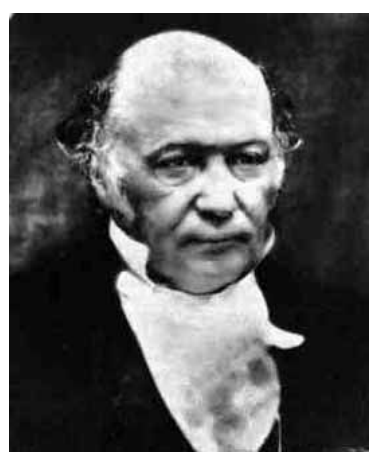

Sir William Hamilton ${ }^{2}$

A few pieces of trivia concerning Hamilton: He could not resist the impulse to carve the formula for the quaternions in the stone of the Broome Bridge as he and his wife passed it. In 1958 the Royal Irish Academy erected a plaque commemorating this as shown in Figure 5. As a child, his linguist uncle James taught him 14 languages, and unfortunately, Hamilton was an alcoholic for the last third of his life.

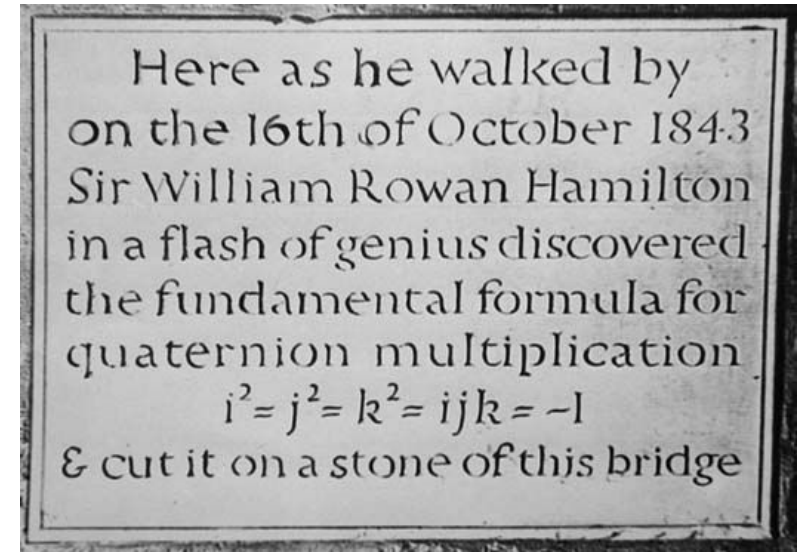

Figure 5. Plaque on the Broome Bridge ${ }^{2}$.

Clearly, the short snippets included here about these giants in the field of dynamics leave out a lot of details and interesting facts. Also, there are others who made significant contributions to the field of dynamics before, during and after the time these men lived, but the ones included above are those whose names will be familiar to most students.

\section{Suggestions on How to Use in Class and Assessment}

There are several ways one can use this historical information to enliven dynamics. It can be used at the beginning of the course as an introduction to the material. Alternatively, the history can be interjected as the course material is being covered. For example, it is natural to discuss the life of Newton or trivia about him when first presenting his laws of motion. When starting on rigid body dynamics, it is natural to discuss Leonhard Euler and how the equations are more 
appropriately referred to as Newton-Euler equations. Gustave-Gaspard Coriolis is a natural to talk about when discussing rigid body kinematics and rotating frames, as well as work-energy methods. In more advanced dynamics courses it is clearly appropriate to discuss Lagrange and Hamilton. These men could also be discussed at the end of the course to show what topics students could expect to see in an upper level course. Another way to incorporate this material is simply to have a "Dynamics throughout history" mini-lecture or slide at the beginning of each week or even each lecture. As students are entering the classroom some piece of historical information or trivia could be projected on a screen for students to read as they prepare for the day's lecture.

When using history and trivia in dynamics, I typically include it on a PowerPoint slide that is being projected as students enter the classroom. Students were surveyed near the end of the quarter about this use of history and trivia. Specifically, the students were asked the following two questions:

Question 1: On a scale from 1 (poor/this is a waste of time) to 5 (excellent/ very interesting), please rate how you feel about this trivia: (circle one)
1
2
3
4
5
neutral
Excellent/very interesting

Poor/waste of time

Question 2: Should I keep doing "trivia of the day" in the future when I teach this class? (circle one)

No No opinion $\quad$ Yes

The results were overwhelmingly positive. Over $85 \%$ of the students indicated that I should continue to do this activity in the course and the overall average was a $4.29 / 5$ with over $47 \%$ of the students rating the history/trivia as "Excellent/very interesting." The general feeling was that this activity did not take very much time - I usually discussed the trivia as I was passing out handouts - and it was interesting and/or humorous and was good way to transition into the material.

Faculty members today are always interested in assessment. That is, does this proposed activity improve student learning? This question is appropriate and reasonable. I am not going to address it, however, because I do not think it can be shown that history and trivia does improve learning of dynamics course material. It does, however, appear to be of interest to students and helps keep them positive and engaged in class, and therefore is a beneficial activity.

\section{Conclusions}

A collection of short historical profiles and trivia has been presented for use by engineering faculty members teaching dynamics. This material can be used to help students understand how old the subject matter being studied truly is and to have an appreciation for the people who made significant contributions in the field of dynamics. Survey results have indicated that students, in general, are very positive about the inclusion of this information in the lectures. 


\section{References}

1. Williams, J.H., Fundamentals of Applied Dynamics, John Wiley \& Sons, Inc., New York, New York, 1996.

2. John J O'Connor, J.J. and E. F. Robertson, The MacTutor History of Mathematics Archive, http://turnbull.mcs.st-and.ac.uk/history/

3. Eric Weissteins' World of Scientific Biography, http://scienceworld.wolfram.com/biography/

4. Allan, D.J., The Philosophy of Aristotle, Oxford: Oxford University Press, 1978.

5. Jaeger, W.W., Aristotle, Oxford: Oxford University Press, 1948.

6. Aristotle, Metaphysic.

7. Aristotle, Nicomachean Ethics

8. Brewster, D., Memoirs of the Life, Writings, and Discoveries of Sir Isaac Newton,1855, reprinted 1965.

9. Encyclopedia Britannica

10. Cajori, F., A History of Mathematical Notations, 1928, reprinted in 1993 by Dover.

11. http://www.kerryr.net/pioneers/gallery/ns_leibniz4.htm

12. Beckmann, P. A, History of Pi, 3rd ed. New York: Dorset Press, 1989 